\title{
A Study on Fiber Laser Welding of High-Manganese Steel for Cryogenic Tanks
}

\author{
Jaewoong Kim, Jisun Kim and Changmin Pyo * \\ Smart Mobility Materials and Components R\&D Group, Korea Institute of Industrial Technology, \\ Gwangju 61012, Korea; kjw0607@kitech.re.kr (J.K.); kimjisun@kitech.re.kr (J.K.) \\ * Correspondence: changmin@kitech.re.kr
}

Received: 4 November 2020; Accepted: 24 November 2020; Published: 25 November 2020

\begin{abstract}
As the environmental regulations on ship emissions by the International Maritime Organization (IMO) become stricter, the demand for a ship powered by liquefied natural gas (LNG) is rapidly increasing worldwide. Compared to other materials, high-manganese steel has the advantages of superior impact toughness at cryogenic temperatures, a low thermal expansion coefficient, and a low-cost base material and welding rod. However, there is a limitation that the mechanical properties of a filler material are worse than those of a base material that has excellent mechanical properties. To solve these shortcomings, a basic study was performed to apply fiber laser welding with little welding deformation and no filler material to high-manganese steel. The relationship between laser welding parameters and penetration shapes was confirmed through cross-section observation and analysis by performing a bead on plate (BOP) test by changing laser power and welding speed, which are the main parameters of laser welding. In addition, the welding performance was evaluated through mechanical property tests (yield strength, tensile strength, hardness, cryogenic impact strength) of a welding part after performing the high-manganese steel laser butt welding experiment. As a result, it was confirmed that the yield strength of a high-manganese steel laser welding part was $97.5 \%$ of that of a base metal, and its tensile strength was $93.5 \%$ of that of a base metal.
\end{abstract}

Keywords: high-manganese steel; bead on plate; cryogenic impact strength; yield strength; tensile strength

\section{Introduction}

The International Maritime Organization (IMO) has decreased the allowable amount of sulfur in fuel oil from $3.5 \% \mathrm{~m} / \mathrm{m}$ (mass by mass) to $0.5 \% \mathrm{~m} / \mathrm{m}$ in 2020 [1]. The reinforced regulation of the IMO can be satisfied when heavy fuel oil (HFO), a typical ship fuel, is replaced by an eco-friendly fuel, natural gas (NG). NG is liquefied at -163 degrees Celsius and its volume is reduced to $1 / 600$, leading to maximized storage and transportation efficiency [2]. The International Code of the Construction and Equipment of Ships Carrying Liquefied Gases in Bulk (IGC Code) limits the materials that can be used for a tank that transports cargo at cryogenic temperatures, and the materials are $9 \%$ nickel steel, STS 304L, Al 5083-O, Invar, and high-manganese steel. These materials have high cryogenic impact toughness to store cryogenic cargo. Table 1 shows the mechanical properties of these materials. 
Table 1. Materials for cryogenic fuels listed in International Code of the Construction and Equipment of Ships Carrying Liquefied Gases in Bulk (IGC Code).

\begin{tabular}{cccc}
\hline Material & Chemical Composition & $\begin{array}{c}\text { Yield Strength } \\
\text { (MPa) }\end{array}$ & $\begin{array}{c}\text { Ultimate Tensile } \\
\text { Strength (MPa) }\end{array}$ \\
\hline 9\% Nickel Steel & Fe-9 Ni & $>585$ & $690-825$ \\
STS304L & Fe-18.5 Cr-9.25 Ni & $>205$ & $>585$ \\
Al5083-O & Al-4.5 Mg & $124-200$ & $276-352$ \\
Invar & Fe-36 Ni & $230-350$ & $400-500$ \\
High-Manganese Steel & Medium C-High Mn & $>400$ & $800-970$ \\
\hline
\end{tabular}

Recently, there has been diverse research on welding technologies for the materials described in Table 1. Kim et al. compared the cryogenic impact strength of welding parts after welding $9 \%$ nickel steel using various welding methods (flux-cored arc welding (FCAW), shielded metal arc welding (SMAW), and submerged arc welding (SAW)) [3]. Park et al. compared the mechanical properties of a welding part with other types of welding after applying the super-TIG welding to $9 \%$ nickel steel [4]. Kim et al. studied the effect of major laser welding parameters on penetration in a laser bead on plate (BOP) test for $9 \%$ nickel steel and compared mechanical properties after performing laser welding and FCAW welding experiments $[5,6]$. Regarding STS304L, Tayebi et al. compared the mechanical properties of welding parts after performing tungsten inert gas (TIG) welding and Nd:YAG laser welding tests for STS304L and STS316L materials [7]. Yang et al. measured the mechanical properties at cryogenic temperatures after performing gas tungsten arc (GTA) welding for the STS304L material using STS308L filler materials [8]. For the A15083-O material used for the MOSS type among liquefied natural gas (LNG) cargo containment systems (CCS), Jang et al. used gas metal arc welding (GMAW) experiment with different combinations of shielding gases and performed comparative evaluation for the mechanical properties of welding parts [9]. Heirani et al. applied friction stir welding (FSW) to the Al5083 material and then checked its microstructure and mechanical properties [10]. Regarding the Invar material, which is a material used for GTT NO96 type among LNG CCS due to its very low thermal expansion coefficient [11], Han evaluated the fatigue strength of a welding part after performing TIG welding on the strake structure of Invar material [12]. Kim et al. derived the optimal conditions of laser welding for the ' + '-shaped Invar structure [13]. The research studies on high-manganese steel are as follows. Velten et al. evaluated mechanical properties after performing heterogeneous welding of high-manganese steel and ferrite steels through laser beam welding [14]. Martin et al. performed structural analysis and evaluated mechanical properties after performing heterogeneous welding of high-manganese and ultra-high strength steels [15]. In this study, laser welding has been assessed for dissimilar material combinations without the filler metal. However, welding defects and mechanical properties in welding zone should be resolved. Han et al. performed structural analysis and performed comparative analysis on mechanical properties after adjusting the carbon content of a welding rod to develop a welding rod of high-manganese steel for cryogenic application [16]. But high-manganese steel cannot be maximized or enjoy good mechanical properties with the filler metal. Han et al. analyzed the tensile strength characteristics by adjusting heat input using a nickel-added high-manganese steel welding rod [17].

There is a limitation that the mechanical properties of a filler material for high-manganese steel are worse than those of a base material that has excellent mechanical properties. In this study, to solve these shortcomings, a basic study was performed to apply fiber laser welding with little welding deformation and no filler material to high-manganese steel. In this study, the penetration characteristics were analyzed after performing a BOP test to apply fiber laser welding, which is easy to automate for high-manganese steel. Then, the physical properties of a welding part were evaluated after welding based on the butt welding conditions obtained from the BOP test. 


\section{Materials and Methods}

The chemical composition of the high-manganese steel used in this study is shown in Table 2. As shown in Table 2, high-manganese steel is a non-metal without magnetism, so it does not have the magnetization phenomenon that usually occurs during welding of $9 \%$ nickel steel with FCAW and etc.

Table 2. Chemical composition of high-manganese steel.

\begin{tabular}{cc}
\hline Component & Percentage (wt.\%) \\
\hline Carbon, C & $0.35-0.55$ \\
Manganese, Mn & $22.0-26.0$ \\
Silicon, Si & $0.3 \max$ \\
Sulfur, S & 0.01 max \\
Chrome, Cr & $3.5-3.0$ \\
\hline
\end{tabular}

For the experiment, a $5 \mathrm{~kW}$ fiber laser weld equipment from Miyachi, Japan was used as shown in Figure 1. The equipment consists of a laser welding oscillator, an optical system, a controller, and a chiller, as shown in Figure 1. The optical system used in this study has a spot diameter of $400 \mu \mathrm{m}$, a focal length of $148.8 \mathrm{~mm}$, and a focal depth of $6 \mathrm{~mm}$. The 6-axis automatic robot was from Yaskawa, Japan, and makes possible the constant focus position of laser welding. The shielding gas was $99.99 \%$ argon with a $15 \mathrm{~L} / \mathrm{min}$ speed.
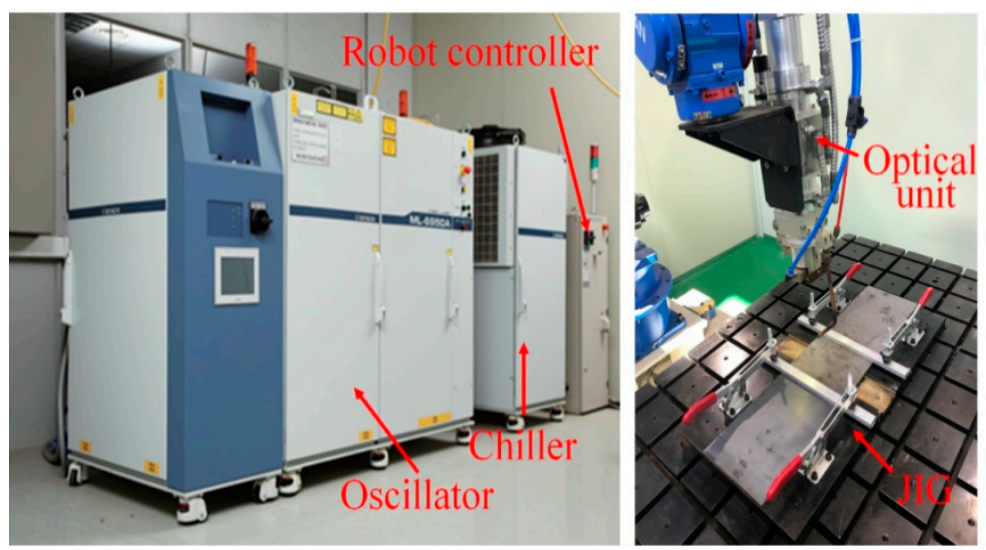

Figure 1. Fiber laser welding equipment.

The fiber laser BOP test specimen of high-manganese steel has the dimension of $300 \mathrm{~mm} \times 300 \mathrm{~mm}$ $\times 15 \mathrm{~mm}$ and the test was performed by cutting the specimen into $25 \mathrm{~mm} \times 10 \mathrm{~mm} \times 15 \mathrm{~mm}$ at the center of the welding length to observe its cross-section, as shown in Figure 2.

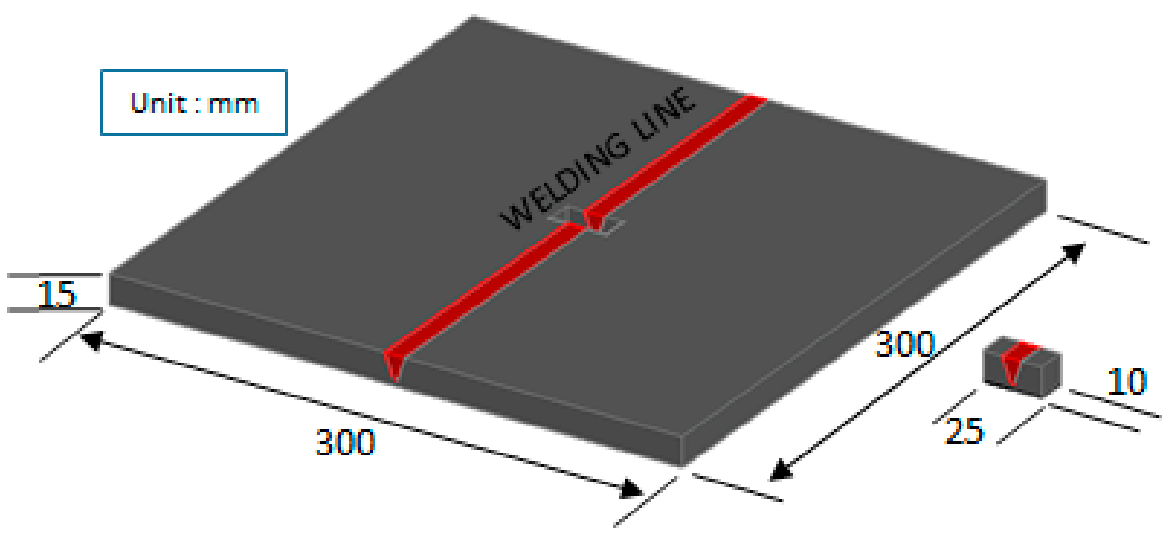

Figure 2. Welding specimen and coupon for cross-section observation. 
The high-manganese steel BOP test was performed a total of 25 times using laser power and welding speed as variables. Each experimental condition is shown in Table 3.

Table 3. Experimental conditions of laser bead on plate (BOP).

\begin{tabular}{cc}
\hline Welding Parameters & Experimental Conditions \\
\hline Laser power $(\mathrm{kW})$ & $1,2,3,4,5(5$ cases $)$ \\
Welding speed (meter per minute, $\left.\mathrm{m} \cdot \mathrm{min}^{-1}\right)$ & $0.50,0.75,1.00,1.25,1.50$ (5 cases) \\
Defocus $(\mathrm{mm})$ & 0 \\
Shielding gas & Ar $99.99 \%, 15 \mathrm{~L} / \mathrm{min}$ \\
Tilting angle \& Working angle & $0^{\circ}$ \\
\hline
\end{tabular}

After the fiber laser BOP test, penetration analysis of high-manganese steel was performed according to macro test ASTM E340 and the environmental conditions were a temperature of 22 degrees Celsius and a humidity of $44 \% \mathrm{RH}$. The specimen was polished to clearly examine the shape of beads, and they are etched with a nital solution (a mixture of 3\% HNO3 and ethanol). The etched cross-section was examined using an optical microscope.

High-manganese steel butt welding was performed using the same specimen size (300 $\mathrm{mm} \times$ $300 \mathrm{~mm} \times 15 \mathrm{~mm}$ ) as shown in Figure 2. After welding, the yield and tensile strength, hardness, and impact tests were performed for a welding part at $-196{ }^{\circ} \mathrm{C}$. Tensile strength tests of the welded zone are carried out using a universal tensile machine (UTM). The yield and tensile strength are evaluated by ASME IX QW code and the test method is as specified in ASTM E8/E8M. In the hardness test, a total of 9 points were measured at intervals of $0.5 \mathrm{~mm}$ at the center of an upper welding part as specified in ASTM E92-17. The impact test in this study is based on a method applied to cryogenic steel specified by IACS (International Association of Classification Societies) and the impact test method of ISO 21028-2: 2004 (en) (toughness requirements for materials at cryogenic temperature).

\section{Results}

\subsection{Cross-Section Observation Results of High-Manganese Steel}

As shown Table 3, 25 BOP cases of cross-section are observed. The observation result of a cross-section after the experiment for each BOP condition is shown in Figures 3-7.

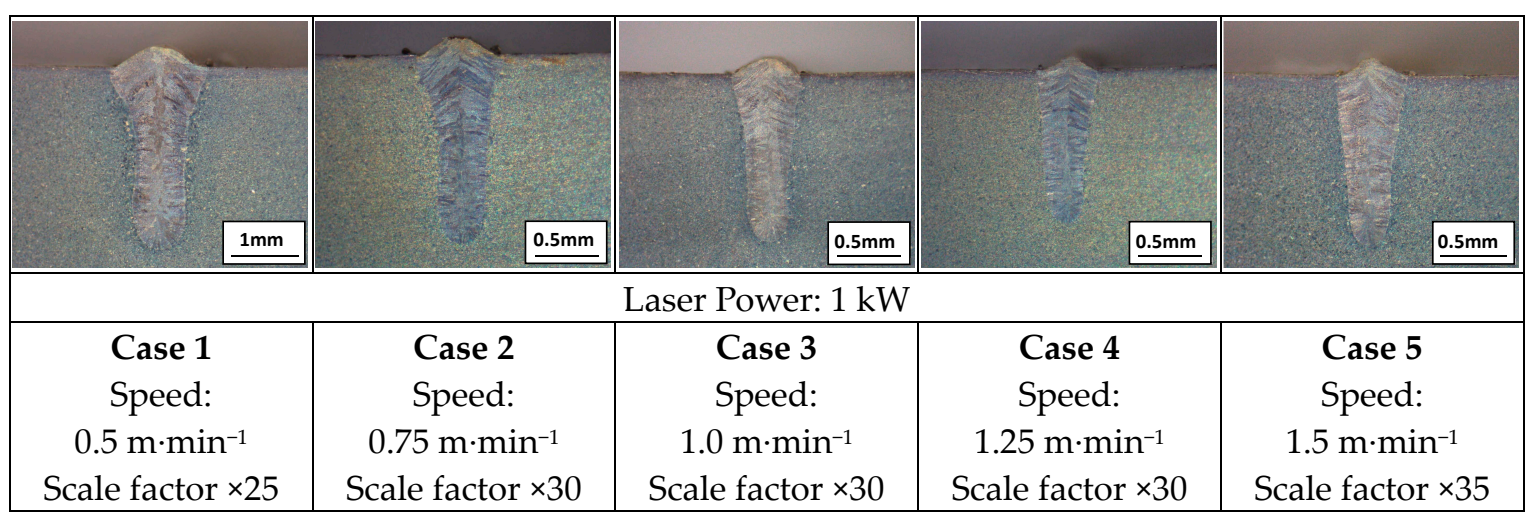

Figure 3. Bead geometry on BOP welding test (laser power: $1 \mathrm{~kW}$, Case 1 5). 


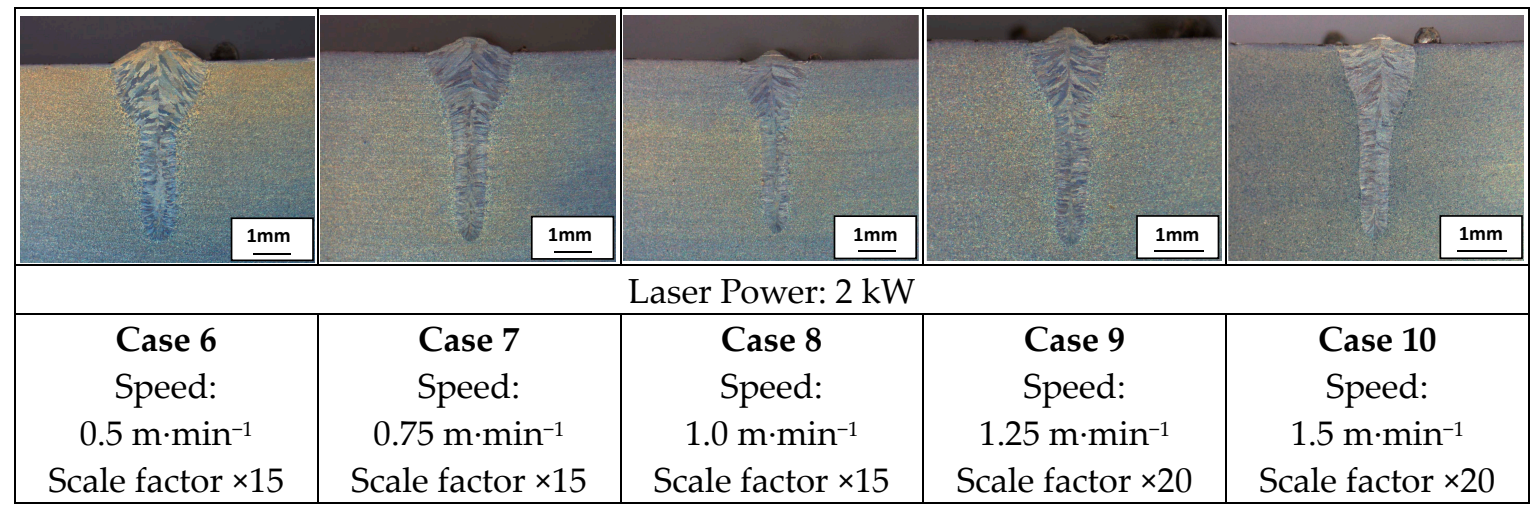

Figure 4. Bead geometry on BOP welding test (laser power: $2 \mathrm{~kW}$, Case 6 10).

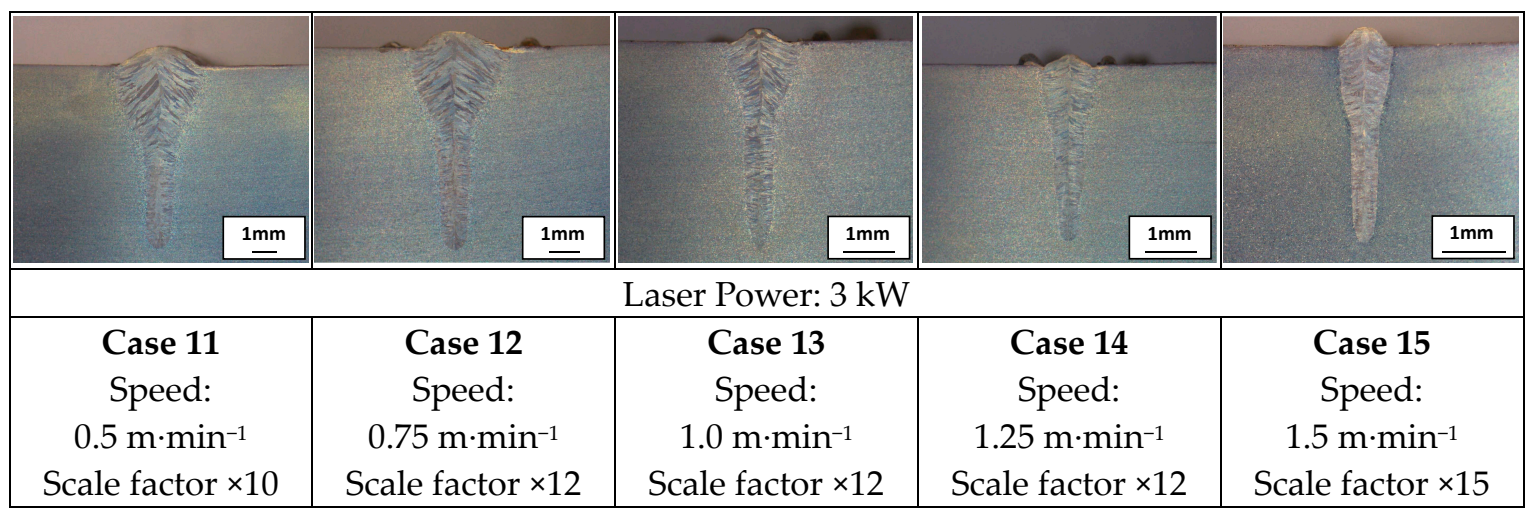

Figure 5. Bead geometry on BOP welding test (laser power: $3 \mathrm{~kW}$, Case 11 15).

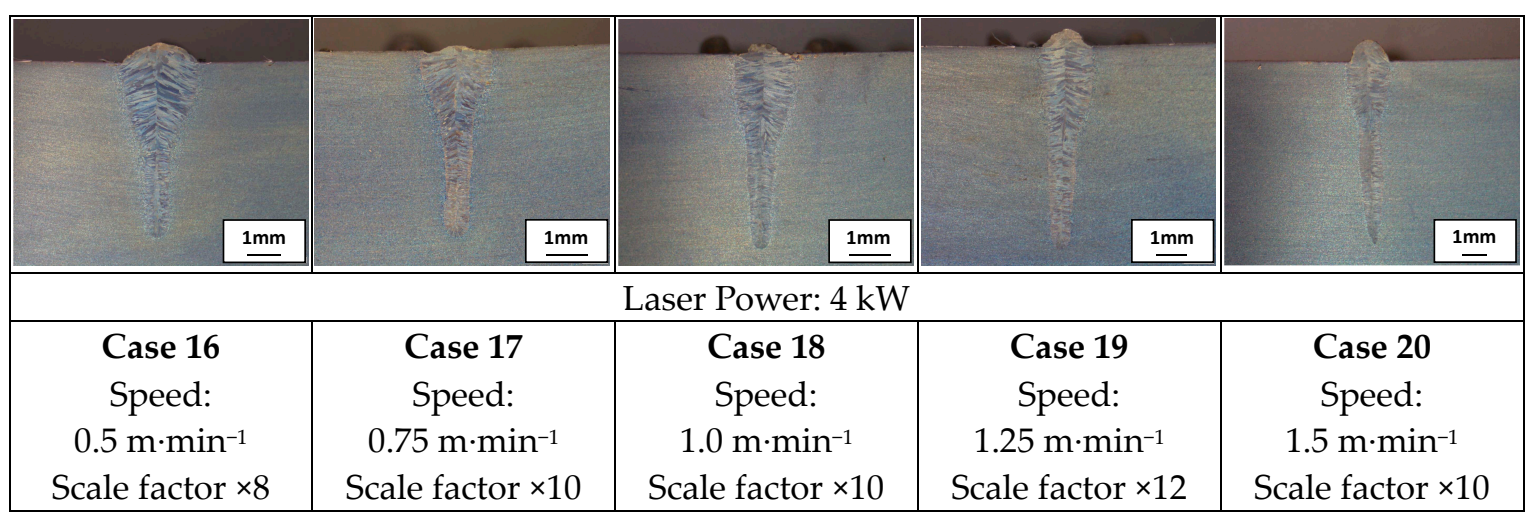

Figure 6. Bead geometry on BOP welding test (laser power: $4 \mathrm{~kW}$, Case 16 20).

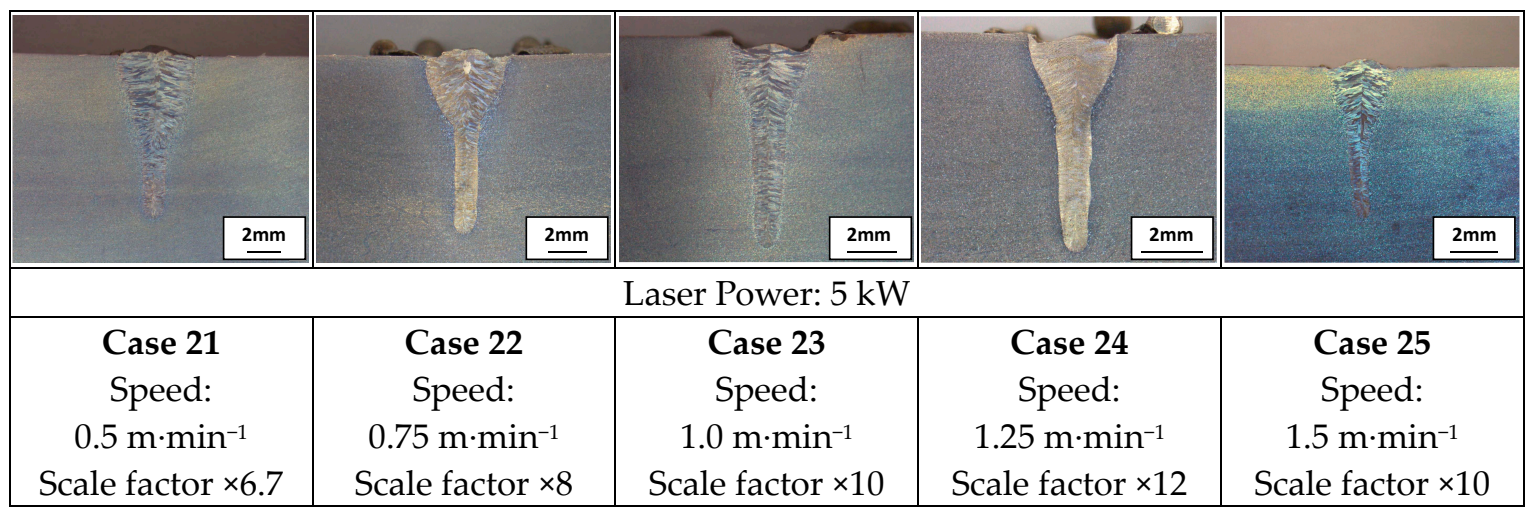

Figure 7. Bead geometry on BOP welding test (laser power: $5 \mathrm{~kW}$, Case 21 25). 
The W (width), H (height), and P (penetration) were measured as shown in Figure 8 through cross-section observation after the high-manganese steel BOP.

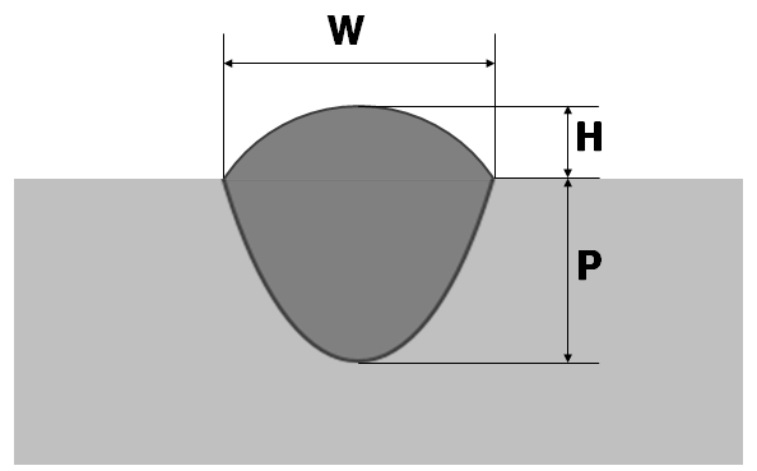

Figure 8. Measurement positions from cross-section observation.

The cross-sectional observation results and measured values for each 25 conditions are shown in Table 4.

Table 4. Experimental conditions of laser BOP.

\begin{tabular}{cccc}
\hline Case & W $\mathbf{( W i d t h}, \mathbf{m m})$ & H (Height, $\mathbf{m m})$ & P (Penetration, $\mathbf{m m})$ \\
\hline $\mathbf{1}$ & 1.885 & 0.346 & 3.154 \\
$\mathbf{2}$ & 1.461 & 0.269 & 2.769 \\
$\mathbf{3}$ & 1.154 & 0.192 & 2.590 \\
$\mathbf{4}$ & 0.962 & 0.154 & 2.269 \\
$\mathbf{5}$ & 0.923 & 0.192 & 2.115 \\
$\mathbf{6}$ & 3.384 & 0.692 & 5.807 \\
$\mathbf{7}$ & 2.692 & 0.423 & 5.307 \\
$\mathbf{8}$ & 2.269 & 0.308 & 4.884 \\
$\mathbf{9}$ & 1.961 & 0.269 & 4.500 \\
$\mathbf{1 0}$ & 1.769 & 0.231 & 3.961 \\
$\mathbf{1 1}$ & 4.192 & 0.808 & 7.807 \\
$\mathbf{1 2}$ & 4.000 & 0.538 & 7.154 \\
$\mathbf{1 3}$ & 3.077 & 0.423 & 7.077 \\
$\mathbf{1 4}$ & 2.308 & 0.346 & 6.154 \\
$\mathbf{1 5}$ & 1.769 & 0.500 & 5.692 \\
$\mathbf{1 6}$ & 5.038 & 1.115 & 9.884 \\
$\mathbf{1 7}$ & 3.231 & 0.192 & 8.115 \\
$\mathbf{1 8}$ & 2.923 & 0.423 & 8.230 \\
$\mathbf{1 9}$ & 2.077 & 0.615 & 7.346 \\
$\mathbf{2 0}$ & 1.923 & 0.885 & 7.654 \\
$\mathbf{2 1}$ & 5.807 & 0.385 & 11.076 \\
$\mathbf{2 2}$ & 5.269 & 0.346 & 9.538 \\
$\mathbf{2 3}$ & 3.961 & -0.308 & 9.153 \\
$\mathbf{2 4}$ & 3.500 & -0.077 & 7.692 \\
$\mathbf{2 5}$ & 3.577 & 0.346 & 6.807 \\
\hline
\end{tabular}

For each welding condition, the measured values of cross-section observation according to laser power were compared and analyzed. The trend of $\mathrm{W}, \mathrm{H}$, and $\mathrm{P}$ values according to laser power increase is shown in Figure 9. 


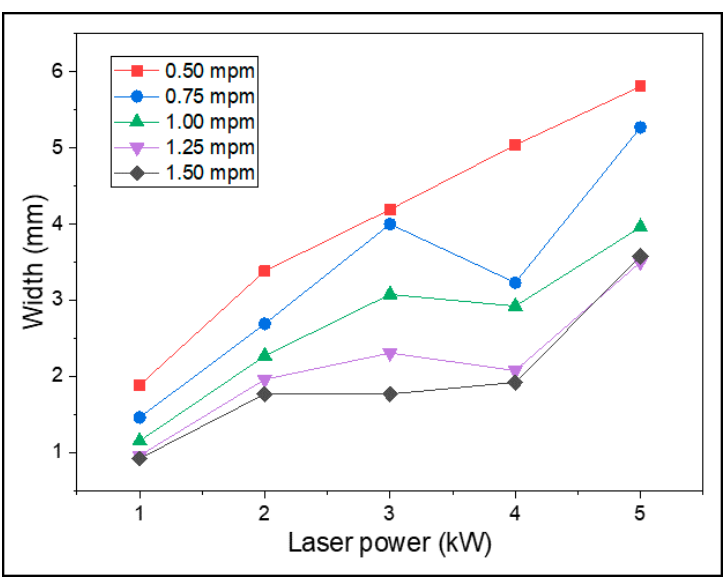

(a)

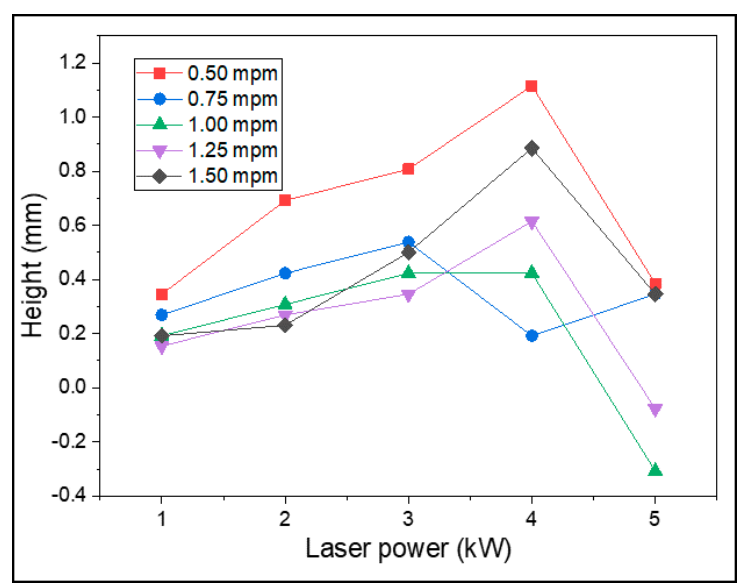

(b)

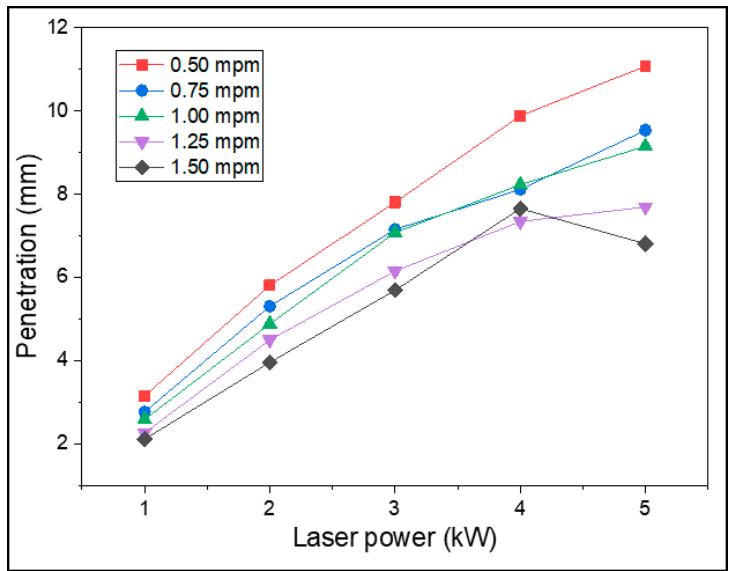

(c)

Figure 9. Bead shape according to laser power: (a) bead width (b) height (c) penetration.

In Figure 9, the (a) Width and (c) Penetration values increase as the laser power increases. In Figure 9b, the Height has negative values in some conditions when the laser power is $4 \mathrm{~kW}$ or $5 \mathrm{~kW}$.

For each welding condition, the measured values from cross-section observation according to welding speed were compared and analyzed. The trend of $\mathrm{W}, \mathrm{H}$, and $\mathrm{P}$ values according to welding speed is shown in Figure 10.

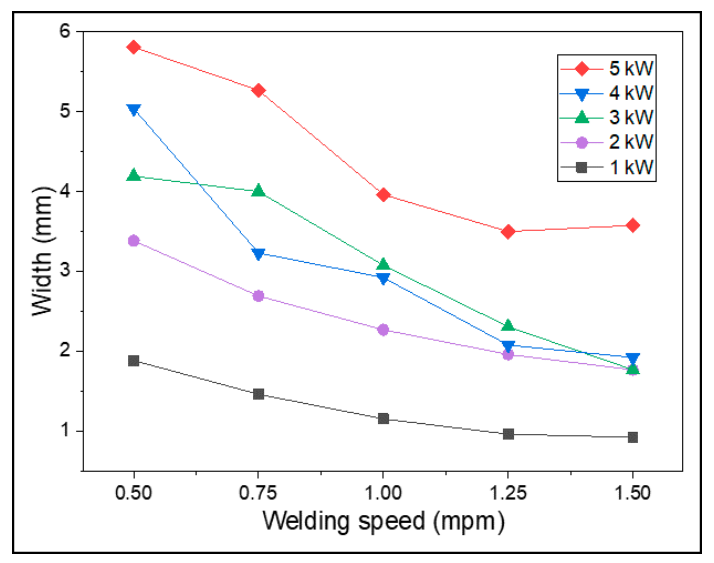

(a)

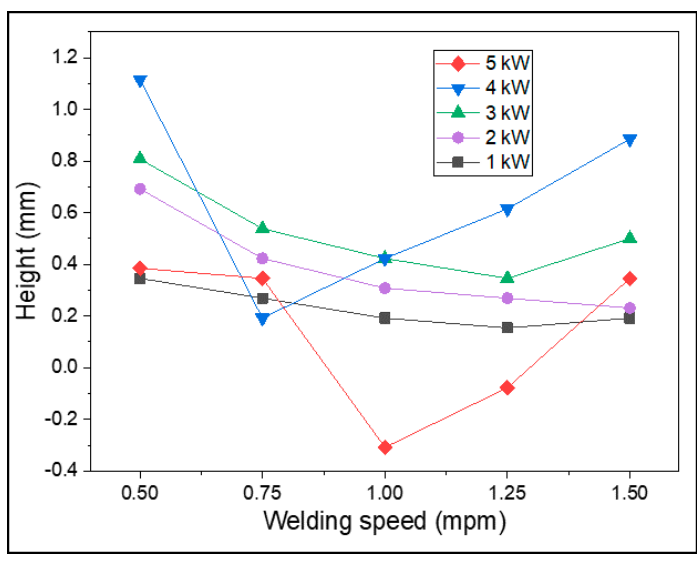

(b)

Figure 10. Cont. 


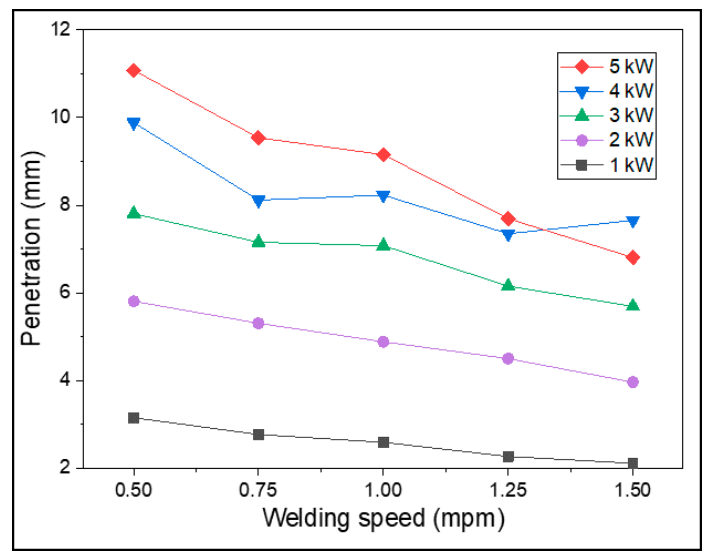

(c)

Figure 10. Bead shape according to welding speed: (a) bead width (b) height (c) penetration.

In Figure 10, the (a) Width and (c) Penetration values decrease as the welding speed increases. In Figure 10b, the Height has negative values in some conditions when the laser power is $4 \mathrm{~kW}$ or $5 \mathrm{~kW}$. This is because high heat input energy was applied to the upper part of a base material during the BOP test, resulting in a defect, where the upper part of a base material was pinched. This condition was excluded from the experimental conditions because it may have caused a welding defect during laser butt welding without a filler metal, which will be performed in the next step.

\subsection{Experiment Results of Fiber Laser Butt Welding for High-Manganese Steel}

After analyzing the fiber laser BOP test results of high-manganese steel obtained in Section 3.1, an experiment was performed after securing the butt 2-pass welding conditions of a high-manganese steel specimen with a thickness of $15 \mathrm{~mm}$ as shown in Table 5. The welding condition was that there was no welding defect in the upper bead and sufficient penetration during 2-pass butt welding using fiber laser welding equipment as shown Figure 11. The welding conditions for each pass (1st pass, 2nd pass) were tested under the same conditions.

Table 5. Butt fiber laser welding conditions of high-manganese steel (15 mm thickness).

\begin{tabular}{ccc}
\hline Case & Laser Power $(\mathbf{k W})$ & Speed $(\mathrm{m} / \mathbf{m i n})$ \\
\hline 1 & 4.00 & 0.500 \\
2 & 4.50 & 0.625 \\
3 & 5.00 & 0.750 \\
\hline
\end{tabular}

The dimensions of a fiber laser butt-welded specimen were $300 \mathrm{~mm} \times 300 \mathrm{~mm} \times 15 \mathrm{~mm}$, the same size as the specimen for which a cross-section was observed.

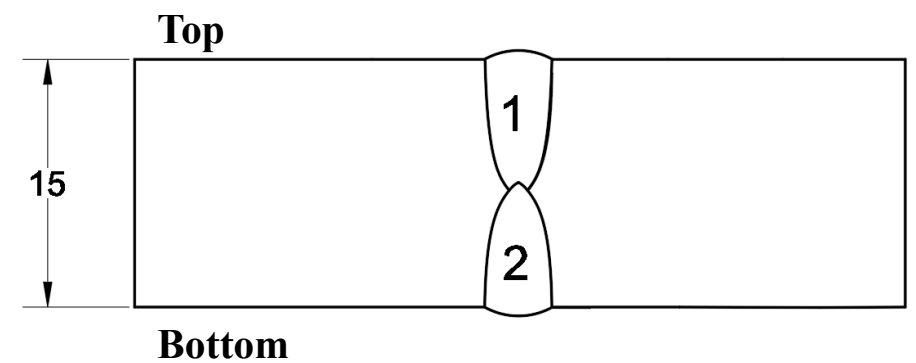

Figure 11. Cross-section of 2-pass butt welding for $15 \mathrm{~mm}$ thickness high-manganese steel by fiber laser equipment. 
The observation results of the cross-section of a welding part after butt welding of high-manganese steels is shown in Figure 12. Each cross-section observation was performing according to ASME Sec. IX-2019(QW-470). From the cross-section observation figures, it can be seen that the upper and lower beads were created for all cases and sufficient penetration was obtained.

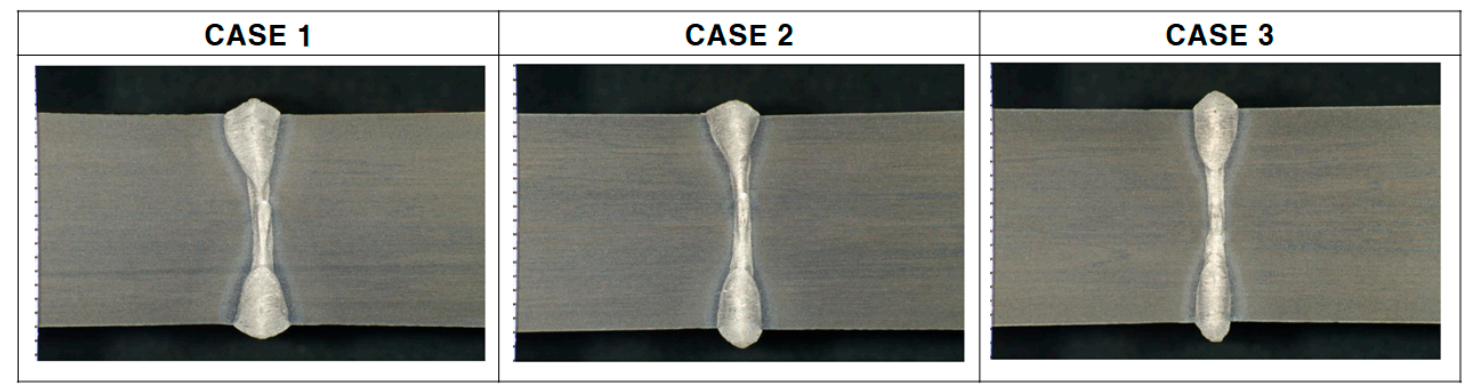

Figure 12. $15 \mathrm{~mm}$ thickness of high-manganese steel welding section observation result for each butt welding case.

The results of the tensile test of a welding part after butt welding of high-manganese steels are shown in Table 6. For each case, the mechanical properties were measured at 1/4, 1/2, and 3/4 depth from the upper surface of a base metal, which is 3 tensile tests per welding. The yield and tensile strength are evaluated by ASME IX QW code and the test method is as specified in ASTM E8/E8M.

Table 6. The results of tensile test of welding part for each laser welding case.

\begin{tabular}{|c|c|c|c|}
\hline CASE \# & Location & Yield Strength (MPa) & Tensile Strength (MPa) \\
\hline \multirow{3}{*}{ CASE 1} & $1 / 4$ & 500 & 838 \\
\hline & $1 / 2$ & 494 & 817 \\
\hline & $3 / 4$ & 488 & 816 \\
\hline \multirow{3}{*}{ CASE 2} & $1 / 4$ & 488 & 851 \\
\hline & $1 / 2$ & 499 & 844 \\
\hline & $3 / 4$ & 493 & 848 \\
\hline \multirow{3}{*}{ CASE 3} & $1 / 4$ & 502 & 839 \\
\hline & $1 / 2$ & 506 & 845 \\
\hline & $3 / 4$ & 501 & 846 \\
\hline Average $=$ & rror range & $496.78 \pm 9.22$ & $838.22 \pm 22.22$ \\
\hline
\end{tabular}

From Table 6, the average yield strength of a welding part is $496.78 \mathrm{MPa}$ and the average tensile strength is 838.22 MPa. Several parameters determine the thickness of LNG fuel tanks, among which the minimum yield and tensile strength is an important factor. The material of high-manganese steel has a disadvantage in that the thickness of the tank becomes thicker due to weakened strength at the weld after welding because of the lower mechanical properties of filler materials [17]. It was found the thickness and weight of a tank can be significantly reduced based on the IGC Code when fiber laser welding is applied to actual cryogenic tank manufacturing.

In this study, for evaluation of the property of hardness, the welds are divided into weld metal, heat-affected zone (HAZ), and base metal, as shown in Figure 9 below to measure a total of 9 points at intervals of $0.5 \mathrm{~mm}$ and the test method is as specified in ASTM E92-17.

The results of the hardness of a welding part after butt welding of high-manganese steels are shown in Table 7. The Arabic number of each measurement location is shown in Figure 13. In total, 27 samples were tested, 9 samples per welding. 
Table 7. Hardness test results for each laser welding case.

\begin{tabular}{cccccccccc}
\hline & \multicolumn{3}{c}{ Base Metal (Hv) } & \multicolumn{3}{c}{ HAZ (Hv) } & \multicolumn{3}{c}{ Weld Metal (Hv) } \\
\cline { 2 - 10 } & $\mathbf{1}$ & $\mathbf{2}$ & $\mathbf{3}$ & $\mathbf{4}$ & $\mathbf{5}$ & $\mathbf{6}$ & $\mathbf{7}$ & $\mathbf{8}$ & $\mathbf{9}$ \\
\hline Case 1 & 233 & 228 & 229 & 252 & 246 & 198 & 185 & 199 & 188 \\
\hline Case 2 & 227 & 223 & 224 & 247 & 240 & 196 & 183 & 190 & 189 \\
\hline Case 3 & 224 & 228 & 227 & 244 & 239 & 200 & 200 & 191 & 195 \\
\hline
\end{tabular}

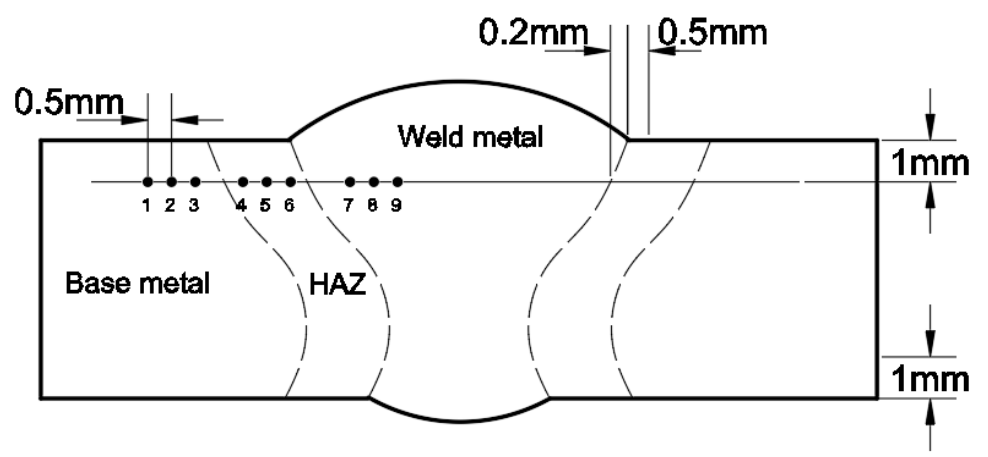

Figure 13. Measurement points of hardness test.

From the hardness test, the hardness for HAZ is generally the largest and the hardness for the weld metal is the smallest.

The impact test in this study is based on a method applied to cryogenic steel specified by ASME Sec. IX-2019(QW-170). The experimental results are also evaluated by the provision that the cushion absorption rate of cryogenic steel in ASTM should exceed $27 \mathrm{~J}$ [18]. In the impact test, $-196{ }^{\circ} \mathrm{C}$ liquid nitrogen is used to create a cryogenic environment and a cryogenic impact test environment is established by immersing the specimen in liquid nitrogen for $5 \mathrm{~min}$ to quench the specimen. The specimen size is $10 \mathrm{~mm} \times 10 \mathrm{~mm}$ and three zones (base metal, HAZ, weld metal) are evaluated three times each (1/4 depth, 1/2 depth, and 3/4 depth from the upper surface of a base metal for each case). The results of the cryogenic impact test after butt welding of high-manganese steels are shown in Table 8. In total, 27 samples were tested, 9 samples per welding.

Table 8. Cryogenic impact test results for each laser welding case.

\begin{tabular}{ccccc}
\hline CASE \# & Location & Base Metal (J) & HAZ (J) & Weld Metal (J) \\
\hline \multirow{3}{*}{ CASE 1} & $1 / 4$ & 131 & 154 & 136 \\
& $1 / 2$ & 119 & 117 & 143 \\
& $3 / 4$ & 121 & 130 & 129 \\
\hline \multirow{3}{*}{ CASE 2 } & $1 / 4$ & 116 & 117 & 70 \\
& $1 / 2$ & 120 & 107 & 66 \\
& $3 / 4$ & 113 & 122 & 62 \\
\hline \multirow{3}{*}{ CASE 3 } & $1 / 4$ & 146 & 137 & 81 \\
& $1 / 2$ & 124 & 150 & 78 \\
& $3 / 4$ & 119 & 131 & 79 \\
\hline
\end{tabular}

From the cryogenic impact test, it was found that all numbers are higher than the ASTM standard $27 \mathrm{~J}$ in all experiments. Except for the CASE 1 experiment, the cryogenic impact strength of the weld metal was relatively lower than that of the base metal part and the HAZ part. 


\section{Discussion}

High-manganese steel has a yield strength of $400 \mathrm{MPa}$ or more and a tensile strength of $800 \mathrm{MPa}-970 \mathrm{MPa}$ according to the manufacturer. In this experiment, the tensile strength of a welding part after fiber laser welding meets the above values. In addition, the tests on the yield strength and tensile strength of a base metal in this experiment were performed three times in the same manner as the welding test and then compared and evaluated. Table 9 shows the test results of yield strength and tensile strength of a base metal.

Table 9. Yield and tensile test results of high-manganese steel base material.

\begin{tabular}{ccc}
\hline CASE \# & Yield Strength (MPa) & Tensile Strength (MPa) \\
\hline Base metal 1 & 513 & 897 \\
\hline Base metal 2 & 511 & 892 \\
\hline Base metal 3 & 504 & 900 \\
\hline Average \pm error range & $\mathbf{5 0 9 . 3 3} \pm \mathbf{5 . 3 3}$ & $\mathbf{8 9 6 . 3 3} \pm \mathbf{4 . 3 3}$ \\
\hline
\end{tabular}

The average yield strength of a high-manganese steel base material is about $509.33 \mathrm{MPa}$ and its average tensile strength is about $896.33 \mathrm{MPa}$. In Table 6, the average yield strength of a laser welding part is $496.78 \mathrm{MPa}$, which is $97.5 \%$ of the base metal, and the average tensile strength is $838.22 \mathrm{MPa}$, which is $93.5 \%$ of the base metal.

When considering that the yield strength of a commercial FCAW filler material of high-manganese steel is $400 \mathrm{MPa}$ or more and its yield strength is $660 \mathrm{MPa}$ or more [16], the current tank thickness can be significantly reduced and it is expected that there will be advantages such as tank cost-saving and weight reduction if fiber laser welding is applied when manufacturing a high-manganese steel tank.

\section{Conclusions}

In this study, fiber laser welding was applied to high-manganese steel, and penetration trend analysis was performed through the BOP test. In addition, butt welding was performed using the welding conditions obtained from the BOP test and the mechanical properties of a welding part were evaluated. Finally, the yield strength and tensile strength of a high-manganese steel base material were evaluated, and then the mechanical properties of a welding part were compared and evaluated. As a result, it was confirmed that the yield strength of a high-manganese steel laser welding part was $97.5 \%$ of that of a base metal, and its tensile strength was $93.5 \%$ of that of a base metal.

Author Contributions: Conceptualization, J.K. (Jaewoong Kim) and J.K. (Jisun Kim); Methodology, J.K. (Jaewoong Kim); Software, J.K. (Jisun Kim); Validation, C.P.; Formal analysis, J.K. (Jisun Kim); Resources, J.K. (Jisun Kim); Data curation, C.P.; Writing —original draft preparation, J.K. (Jaewoong Kim); Writing—review and editing, J.K. (Jaewoong Kim); Visualization, J.K. (Jaewoong Kim); Project administration, J.K. (Jaewoong Kim); All authors have read and agreed to the published version of the manuscript.

Funding: This research has been conducted with the support of the Ministry of Trade, Industry and Energy, Republic of Korea, as "Development of small and medium LNG fuel storage module for coastal ship" in the material parts technology development project.

Conflicts of Interest: The authors declare no conflict of interest.

\section{References}

1. Li, K.; Wu, M.; Gu, X.; Yuen, K.; Xiao, Y. Determinants of ship operators' options for compliance with IMO 2020. Transp. Res. Part D Transp. Environ. 2020, 86, 102459. [CrossRef]

2. Choi, Y.; Ahn, J.; Jo, C.; Chang, D. Prismatic pressure vessel with stiffened-plate structures for fuel storage in LNG-fueled ship. Ocean Eng. 2020, 196, 106829. [CrossRef]

3. Kim, B.; Park, J.; Lee, J.; Kim, M. Study on the Initial Design of an LNG Fuel Tank using 9\% wt.\% Nickel Steel for Ships and Performance Evaluation of the Welded Joint. J. Weld. Join. 2019, 37, 555-563. [CrossRef] 
4. Park, J.; Kim, Y.; Baek, H.; Cho, S. A study on process development of super-TIG welding for $9 \%$ nickel steel with Alloy 625. J. Manuf. Process. 2019, 40, 140-148. [CrossRef]

5. Kim, J.; Kim, J.; Kang, S.; Chun, K. Laser Welding of ASTM A553-1 (9\% Nickel Steel) (PART I: Penetration Shape by Bead on Plate). Metals 2020, 10, 484. [CrossRef]

6. Kim, J.; Kim, J. Laser Welding of ASTM A553-1 (9\% Nickel Steel) (PART II: Comparison of Mechanical Properties with FCAW). Metals 2020, 10, 999. [CrossRef]

7. Tayebi, M.; Soltani, H. Comparative study of AISI 304L to AISI 316L stainless steels joints by TIG and Nd:YAG laser welding. J. Alloys Compd. 2018, 767, 112-121. [CrossRef]

8. Yang, W.; Kil, W.; Moon, B.; Nam, H. Tensile and Microstructural Behaviors of Austenitic Stainless Steel GTA Welds for Cryogenic Application. J. Weld. Join. 2020, 38, 400-408. [CrossRef]

9. Jang, K.; Lee, D.; Kuk, J.; Kim, I. Welding and environmental test condition effect in weldability and strength of Al alloy. J. Mater. Process. Technol. 2005, 164, 1038-1045. [CrossRef]

10. Heirani, F.; Abbasi, A.; Ardestani, M. Effects of processing parameters on microstructure and mechanical behaviors of underwater friction stir welding of Al5083 alloy. J. Manuf. Process. 2017, 25, 77-84. [CrossRef]

11. Nohara, K.; Ejima, A. Fe-36\% Ni invar type alloy KLN 36 for LNG Facilities. Kawasaki Steel Tech. Rep. 1985, 13, 97-108.

12. Han, J. A study on application of corrugated invar strake edge in the membrane cargo containment of LNG carriers. J. KWJS 2009, 27, 74-80.

13. Kim, D.S.; Pyo, C.; Kim, J.; Kim, J.; Lee, H.-K. A Study on Cross-Shaped Structure of Invar Material Using Cold Wire Laser Fillet Welding (PART I: Feasibility Study for Weldability). Metals 2020, 10, 1385. [CrossRef]

14. Velten, B.; Matthias, H.; Ansgar, H.; Andre, S.; Stenfan, K.; David, H.; Manuel, O.; Ludger, O. Investigations on Laser Beam Welding Dissimilar Material Combinations of Austenitic High Manganese (FeMn) and Ferrite Steels. Phys. Procedia 2014, 56, 610-619. [CrossRef]

15. Martin, D.; Stefan, L.; Damien, M.; Dirk, P. Weld Metallurgy and Mechanical Properties of High Manganese Ultra-high Strength Steel Dissimilar Welds. Phys. Procedia 2016, 83, 344-351. [CrossRef]

16. Han, I.; Lee, B.; Choi, J.; Park, S. Microstructure and Mechanical Properties of Cryogenic High-Manganese Steel Weld Metal. Int. J. Offshore Polar Eng. 2013, 27, 348-352. [CrossRef]

17. Han, I.; Yun, J.; Lee, B.; Kang, J. Effect of Tensile Properties and Microstructure on the Heat Input of Ni-Doped High Manganese Welding Wire. J. Weld. Join. 2018, 36, 10-17. [CrossRef]

18. Kim, E.; Park, J.Y.; Lee, J.S.; Lee, J.I.; Kim, M.H. Effects of the welding process and consumables on the fracture behavior of 9 wt.\% nickel steel. Exp. Tech. Sept. 2019, 44, 1-12. [CrossRef]

Publisher's Note: MDPI stays neutral with regard to jurisdictional claims in published maps and institutional affiliations.

(C) 2020 by the authors. Licensee MDPI, Basel, Switzerland. This article is an open access article distributed under the terms and conditions of the Creative Commons Attribution (CC BY) license (http://creativecommons.org/licenses/by/4.0/). 